\title{
Predictors for HCV treatment outcome: lower limit of quantification vs. limit of detection
}

\author{
B.C.M. Conjaerts \\ Department of Medical Microbiology MUMC+, Maastricht University \\ b.conjaerts@student.maastrichtuniversity.nl
}

\begin{abstract}
Introduction. In HCV treatment, the early on-treatment virological status is used as guideline for response guided therapy (RGT) and is the key predictor for a sustained virological response (SVR). The response to treatment (RT) is determined by HCV RNA results at week 4 and 12 of treatment. Being 'undetectable' at these time points, is a reliable predictor for reaching a SVR. To define an 'undetectable' HCV RNA, the lower limit of quantification (LOO) and not the limit of detection (LOD) is used. This leaves a gray zone between the LOO and the LOD, which results in a 'detectable but no quantifiable' (DNO) HCV RNA to be reported as 'undetectable'. The aim of this study is to analyse the reliability of using the LOQ at key decision time points, week 4 (Rapid viral response; RVR) and week 12 ( Early viral response; EVR) to predict treatment outcome.

Methods. Retrospective analysis of the response to therapy, treatment outcome and SVR of patients treated for HCV. In the period Oct 2012 - Apr 2013, HCV RNA samples were conducted at week 4,12, end of treatment (EOT) and 24 weeks after treatment and tested with the Ampliprep/Cobas-Taqman_HCV-test-v1.O. (Limit of detection; LOD: $15 \mathrm{IU} / \mathrm{ml}$, Lower limit of quantification; LOQ: $43 \mathrm{IU} / \mathrm{ml}$ ).

Results. In total, 19 patients were treated, of which 10 relapsed and 9 cleared the virus. In both treatment outcome groups, DNQ HCV RNA statuses were observed. Treatment outcome showed no relation between having a DNQ during treatment $(p=0,350)$ or at decision time points, $4^{\text {th }}$ week $(p=0,167)$ or $12^{\text {th }}$ week $(p=0,474)$. In contrast, a on-treatment viral status $>L O Q$ and $\angle L O D$ showed a relation with treatment outcome at week $4(p=0,007)$, but not at week $12(p=0,474)$. In addition, the response to therapy (RVR or EVR) showed a relation with reaching SVR $(p=0,023)$, which was not influenced by the on-treatment viral status; DNO.

Conclusion. Reaching an 'undetectable' HCV RNA result at week 4 and/or week 12, is not always a guarantee of achieving SVR. In our study, being 'detectable but not quantifiable'
\end{abstract}


at decision time point does not give a higher incidence of relapsing. The HCV RNA being 'detectable but not quantifiable' does not influence the predictive value of a Rapid or Early viral response. Therefore, our study suggests that no alterations in the decision-rules for $\mathrm{HCV}$ guidelines have to be carried out.

\section{Keywords}

HCV, Limit of quantification (LOQ), Sustained viral response (SVR), Relapse, Viral load.

\section{Abbreviations and descriptions:}

RVR : Rapid viral response: an undetectable viral load after 4 weeks treatment. EVR: Early viral response: undetectable viral load or drop by $99 \%$ after 12 weeks of treatment. SVR: Sustained viral response: undetectable viral load 24 weeks (SVR-24) after treatment ended. EOT: End of treatment. Relapse: Someone whose viral load becomes undetectable on treatment but rebounds after stopping it. LOD: Limit of detection: lowest HCV level detectable in $>95 \%$ of the cases, eg. $15 \mathrm{IU} / \mathrm{ml}$ LOQ: Lower limit of quantification: Lowest HCV level within the linear and analytically acceptable range of the assay, eg. Lower limit of quantification: $43 \mathrm{IU} / \mathrm{ml}$. DNO: Detectable/not quantifiable: HCV level between LOD and LOQ, eg 15-43 IU/ml. Quantifiable : >43 IU/ml. Undetectable: $<15 \mathrm{IU} / \mathrm{ml}$

\section{Introduction}

The hepatitis C virus (HCV) is a positive sense, single stranded enveloped RNA virus, classified in the Hepacivirus genus within the Flaviviridae family. The virus is associated with low-density lipoproteins (LDL) and very-low-density lipoproteins (VLDL) and binds to plasma lipoproteins to form complex lipoviroparticles (LVP) (1). These lipidprotein containing particles bind to LDL-receptors and can be found on different cells, but are especially known to reside on hepatocytes (2). Once in the hepatocytes, the virus replicates itself and exits the cell similar to the VLDL pathway, one of the most important liver secretion pathways (3). Due to the high affinity with hepatic cells, HCV mostly infects the liver and causes acute and chronic hepatitis. Eighty percent of the acute hepatitis $\mathrm{C}$ infections eventually proceed to a chronic liver infection. HCV initiates inflammation and damages the hepatocytes, causing cirrhosis in 10-20\% of the cases, which ultimately could lead to hepatocellular carcinoma (1-5\% prevalence). The problem with an acute and chronic HCV infection is its mostly asymptomatic character. This makes it difficult to trace infected people.

Next to this, HCV infection is not bound to specific geologic areas or populations and has a worldwide distribution, which is non-specific for age, gender or race. This explains 
why the prevalence of people who have been infected during life, is estimated on 130-170 million persons, which resembles $2-3 \%$ of world population (4). In the Netherlands the HCV seroprevalence reaches an estimated $0.22 \%$, corresponding to $28,100 \mathrm{HCV}$ infected individuals (5).

\section{Treatment of HCV}

Regarding the prevalence of HCV in the world population of an estimated $2-3 \%$ (4), and the possible development of cirrhosis and eventually liver cancer, makes HCV a worldwide health problem. Chronic HCV treatment on itself is a health care economic burden. Next to this, the HCV infection may develop complications, including cirrhosis and liver cancer, which increase direct and indirect health care costs. The standard treatment with Pegylated interferon $a 2 a$ or $a 2 b$ and Ribavirin has shown to be cost-effective, unfortunately it has a lot of side effects and needs a long duration of treatment (approximately 48 weeks) $(6,7)$. The latest advances on HCV treatment are direct-acting antiviral (DAA) agents. These DAA agents are the NS3/4A serine protease inhibitors Boceprevir (BOC) and Telaprevir (TVR) which are used in combination with PegIFN and Ribavirin in triple therapy. It is recommended to use this triple therapy in combination with Reponse Guided therapy (RGT). While the HCV viral load is believed to represent the balance between viral replication and clearance (8), the HCV viral load is used as benchmark for the responsiveness of the patient to the given treatment.

The response is measured on the $4^{\text {th }}$ and $12^{\text {th }}$ week of treatment, of which the $4^{\text {th }}$ week of treatment has shown to be the most valuable on-treatment predictor for a sustained viral response (SVR) (9). A Rapid viral response (RVR) and early viral response (EVR) are defined as an undetectable HCV viral load at $4^{\text {th }}$ week and $12^{\text {th }}$ week of treatment respectively, and are taken in account when evaluating the response to treatment (RT). The RVR and EVR are the parameters on which treatment recommendations are based regarding the practice guidelines by the American Association of the study of liver Diseases (AASLD) (7).

\section{Techniques and method}

The duration and continuation of treatment are based on response to treatment and depend on evaluation of the HCV RNA levels. Therefore, measurement and interpretation of the HCV RNA levels during treatment have become extremely relevant. Especially the differentiation between 'undetectable' and 'detectable/ not quantifiable' HCV RNA deserves attention. To measure the HCV RNA levels, a blood sample is drawn and tested for the viral RNA load with a reverse transcriptase quantification polymerase chain reaction (RT-qPCR) assay (8). Depending on the assay used, certain performance characteristics are 
assumed. The MUMC+ uses the Roche Cobas ${ }^{\circledR}$ Ampliprep/ Cobas ${ }^{\circledR}$ Taqman 48 V 1,0 and its characteristics to determine the HCV viral load. This assay uses a viral load quantification range of $43-69000000 \mathrm{IU} / \mathrm{ml}$ indicating the range wherein the HCV RNA Load is quantifiable. The value $43 \mathrm{IU} / \mathrm{ml}$ is used as limit of quantification (LOO) and beneath this value a sample is reported as undetectable, conform the limit used in the Roche Cobas RTPCR assay. In contrast, the limit of detection (LOD) is set at $15 \mathrm{lU} / \mathrm{ml}$ and is defined as the lowest HCV RNA level that is still detectable by the assay in $>95 \%$ of the cases. This leaves the gray zone $15-43 \mathrm{IU} / \mathrm{ml}$ in which the HCV RNA level is detectable but not quantifiable (DNO). Nevertheless, the LOQ is used as cut-off point in RGT and to define a sustained virological response (SVR) 24 weeks after end of treatment (9).

However, a study on the treatment of HCV suggested that patients with a detectable, but not quantifiable HCV RNA (DNQ), had significantly lower SVR rates compared to patients whose HCV RNA was not detectable at the same time point $(9,10)$. This means these patients should receive a different reccomendation on treatment duration according to the practice guidelines by the AASLD (8).

Therefore we wanted to assess the reliability of using the lower limit of quantification (LOQ) as limit and predictor for treatment outcome. This study is important to confirm the published data and to change the decision-rules in the treatment of patients with $\mathrm{HCV}$ in Maastricht UMC+.

\section{Material and methods}

For the period October $1^{\text {st }}$ 2012-April $1^{\text {st }}$ 2013, the laboratory results for HCV-RNA measurement were collected. Patients who requested at least one HCV PCR within this timeframe were included in the database.

\section{Patients.}

For a total of 356 patients, a HCV-PCR was requested in the period of October 2012 until April 2013. Inclusion criteria; patients reported a detectable HCV viral load (>43 IU/ml) followed by an undetectable load $(<43 \mathrm{IU} / \mathrm{ml})$. The included patients started treatment, were treated during or ended treatment 24 weeks prior to this period. If not meeting these criteria or in absence of data, the patient was excluded. The HCV viral load, response to treatment and treatment outcome of 19 patients was evaluated.

\section{Analysis of virological outcome.}

The viral load was evaluated on key decision time points; $4^{\text {th }}$ and $12^{\text {th }}$ week of treatment, end of treatment (EOT) and follow up on virological endpoint. The primary virological endpoint was defined as an undetectable HCV RNA result 24 weeks after end of anti-viral treatment (SVR24). 


\section{HCV viral load quantification.}

To quantify the RNA load, the Roche Cobas ${ }^{\circledR}$ Ampliprep/ Cobas ${ }^{\circledR}$ Taqman 48 RT-qPCR was used. The COBAS $^{\circledR}$ RT-qPCR is based on the reverse transcription and at the same time the amplification of the HCV CDNA. As preparation, the serum or plasma were separated by centrifugation and loaded into the Cobas Ampliprep for sample preparation. Reagents and auxiliary supplied by the Roche Cobas ${ }^{\circledR}$ Ampliprep/COBAS ${ }^{\circledR}$ Taqman 48 , together with the samples, negative and positive controls, were then loaded according the standardized MUMC+ SOP*.

The Roche Cobas $^{\circledR}$ Ampliprep/COBAS ${ }^{\circledR}$ Taqman 48 reported a target undetectable whenever the results were below the Limit of detection (LOD) or below the lower limit of quantification (LOO) and were registered as $\langle 43 \mathrm{IU} / \mathrm{ml}$. The values between the $\mathrm{LOO}$ and LOD, $43 \mathrm{IU} / \mathrm{ml}$ and $15 \mathrm{IU} / \mathrm{ml}$ respectively, were reported undetectable but gave a positive signal and estimated value (DNQ; detectable/not quantifiable). Above the LOQ (43 IU/ml) the results were quantifiable and documented in the absolute value.

\section{Results}

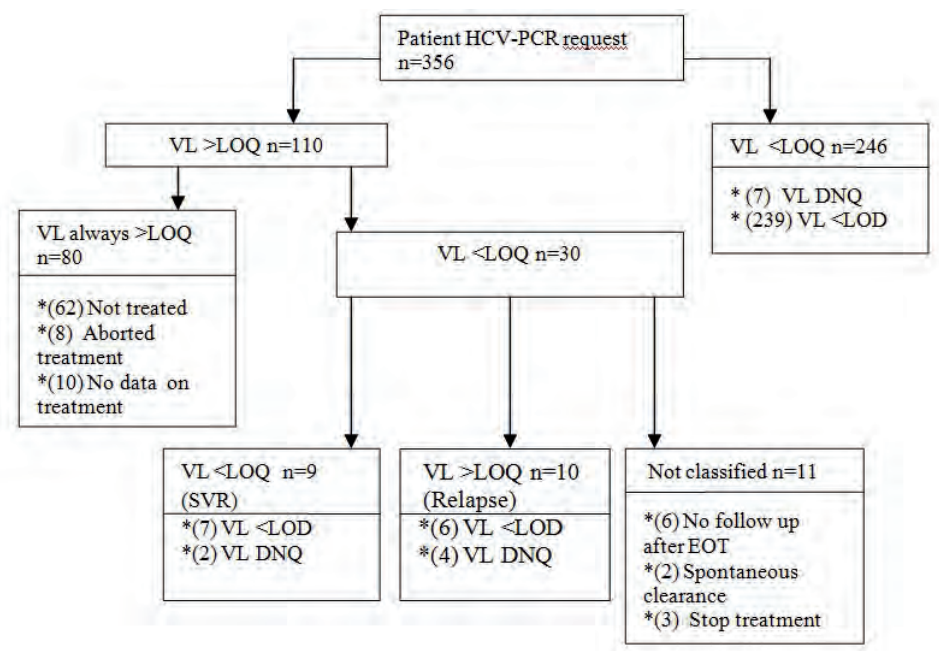

Figure 1. Categorization of all patients with at least one HCV- PCR request in the period October 2012- April 2013. Number of patients with a HCV-PCR request in the MUMC+ in the period 2012-2013. Categorization was based on HCV PCR results. VL >LOQ; HCV VL >43 IU/mI. VL <LOQ; HCV VL $\leq 43 \mathrm{IU} / \mathrm{ml}$. DNO; HCV VL between $15 \mathrm{IU} / \mathrm{ml}$ and $43 \mathrm{IU} / \mathrm{ml}$. EOT; end of treatment VL; Viral HCV RNA load. SVR; sustained viral response. Relapse; detectable 24 weeks after treatment. For 10 patients in the VL always >LOQ group, no data about their treatment was available. 


\section{Based on PCR results}

To get a clear overview of the course of HCV infection and treatment, we used the patient's medical history on HCV. We found that in the MUMC+ for 356 patients, at least one HCVPCR was requested in the period of October 2012 until April 2013 (Figure 2). In 246 patients, all requested HCV- PCRs had a HCV viral load beneath the LOQ. Within this group, the viral load of 7 patients was DNO and 239 were undetectable ( $<L O D)$. The remaining 110 patients had at least one detectable viral load, above the limit of quantification (LOO $>43 \mathrm{IU} / \mathrm{ml}$ ), during the determined period. The HCV PCR results never had HCV RNA below LOO in case of 80 patients, even though some patients were treated during the investigated period. The HCV RNA results were at least once undetectable $(<L O D)$ for 30 patients. Of these 30 patients, in 9 patients the undetectable viral load sustained until 24 weeks after treatment or longer. In 10 patients, the HCV RNA became detectable after EOT and was classified as relapser. Eleven patients were not classifiable. Of these 11, 6 did not receive follow up on HCV RNA after EOT, of whom 3 did not reach SVR24 yet, 2 moved to a other region and 1 did not came to the appointments. In total, 3 patients stopped treatment early due to a nonresponse at 12 weeks $(n=2)$ and a breakthrough of the virus $(n=1)$. The remaining 2 patients had a spontaneous clearance and were not treated during this period (Figure 1).

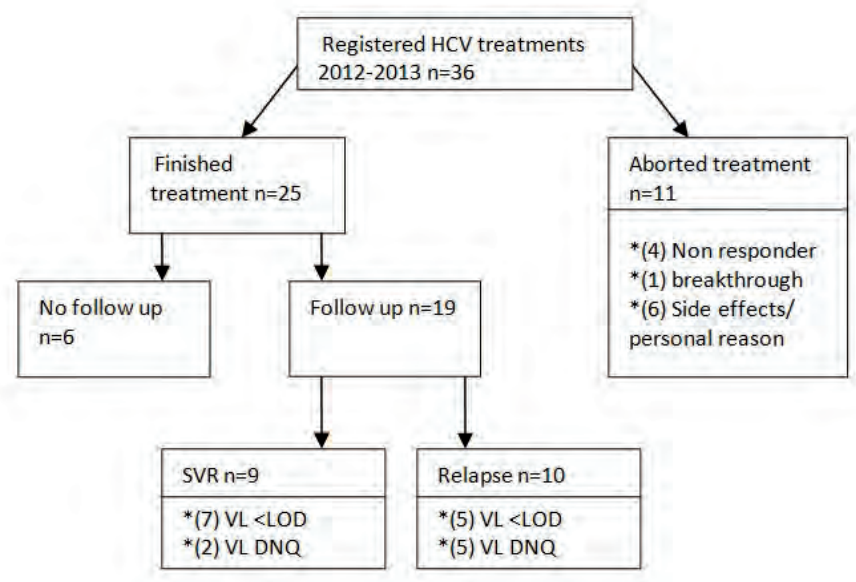

Figure 2. Categorization of patients based on response and outcome of treatment. Number of patients that were treated and had a HCV-PCR request in the period October 2012-April 2013. Categorization based on the course of treatment and HCV PCR results. Finished treatment; recommended treatment period completed. Aborted treatment; HCV treatment ended before recommended treatment period. Follow up was done at 24 weeks after EOT. Relapse; no SVR after EOT. VL <LOQ; HCV VL $\leq 43 \mathrm{IU} / \mathrm{ml}$. DNQ; HCV VL between $15 \mathrm{IU} / \mathrm{ml}$ and $43 \mathrm{IU} / \mathrm{ml}$. VL; Viral HCV load. 


\section{Based on treatment history}

When evaluating the treatment history of the patients, only 36 patients out of the 110 detectable reported patients, were treated during the determined period. Out of 36 patients, 25 patients finished their HCV treatment. The remaining 11 had to abort treatment early due to non response to treatment, unacceptable side effects or a breakthrough of the HCV virus. In the case of 6 treated patients, there was no data found on SVR follow up, therefore the treatment outcome is not known. As a result, the groups "No follow up" and "Aborted treatment" will not be mentioned in more detail and are not included in the study (Figure 2).

Of the 19 patients who received follow up on their finished treatment, 9 had a SVR at 24 weeks and 10 patients had a relapse (No SVR) within 24 weeks after treatment. Of these 10 patients without a SVR, 5 patients had HCV viral loads $\angle L O D$ and 5 patients had at least one DNQ HCV RNA result. Within the SVR patient group, 2 reported a DNQ HCV RNA and 7 were always below LOD (Figure 2).

During treatment, multiple HCV-PCRs were performed and mostly done on predetermined time points. The viral load was evaluated at the start of the treatment, at $4^{\text {th }}$ week of treatment, $12^{\text {th }}$ week of treatment, end of treatment and follow up (SVR24). For example, the HCV RNA changes of a relapsing patient (during treatment) show the decrease followed by an increase of HCV RNA (Figure 3).

\section{HCV RNA change during treatment of patient 1}

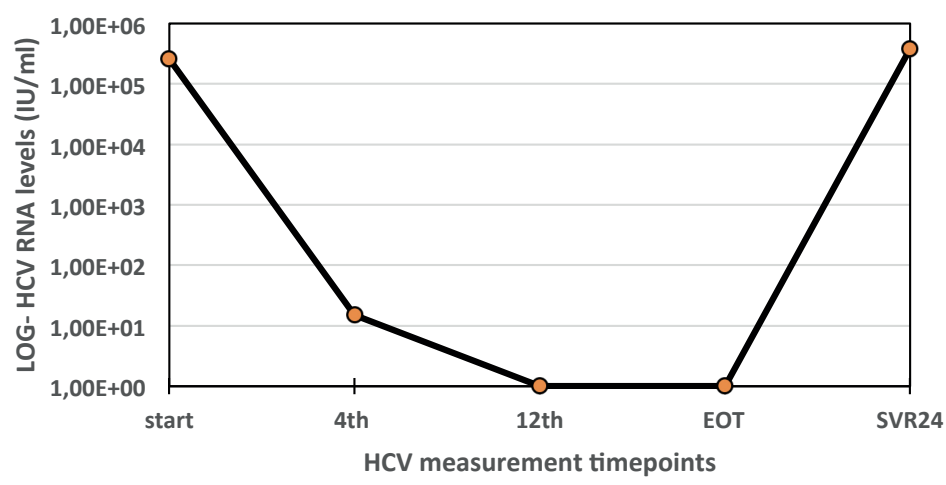

Figure 3. Course of HCV RNA levels during treatment and follow up of a relapsed patient. Values are given in LOG. ${ }^{*}$ Indicates $1,00+00$ is used for value 0,00 in graph. Start; $\mathrm{HCV}$ at start of treatment. $4^{\text {th }}$ week of treatment. $12^{\text {th }}$ week of treatment. EOT; end of treatment. SVR24; follow up 24 weeks after EOT. 


\section{RVR and EVR.}

All patients with follow up were categorized in rapid viral response (RVR) and early viral response (EVR).

\section{Rapid viral response (RVR).}

At week 4 the response of therapy was evaluated to see whether the patient had a RVR. At the $4^{\text {th }}$ week a total of 10 patients had a HCV level $>$ LOO, therefore these patients did not have a RVR. The remaining 9 patients did have a HCV level $\angle L O Q$ and the response was classified as RVR. Of these 9 patients, 5 had a HCV RNA <LOD and of 4 patients the HCV RNA was DNO. Regarding treatment outcome of these 9 patients, 7 patients had a SVR and 2 relapsed after EOT. DNO HCV RNA was reported in 2 patients with a SVR and 2 patients that relapsed. The remaining 5 patients with a SVR had HCV RNA $\angle L O D$. These results show a relation between treatment outcome and having a HCV RNA $>L O Q$ or $\angle L O D$ at 4 weeks of treatment $(p=0,007)$. In contrast, there was no relation for treatment outcome and DNO $(p=0,167)$ at week 4 . (Table 1)

Table 1. Sustained viral response (SVR) and Relapse rates according the on-treatment viral load status at decision time points and response to treatment.

\begin{tabular}{|c|c|c|c|c|c|c|}
\hline \multicolumn{2}{|c|}{ Response to treatment (RT) } & \multicolumn{2}{|l|}{ Relapse rate $\mathbf{N}(\%)$} & \multicolumn{3}{|c|}{ SVR Rate N (\%) } \\
\hline RVR * & $4^{\text {th }}$ week & $2 / 10(20 \%)$ & & $7 / 9$ (78\%) & & \\
\hline & DNQ & $2 / 10$ & $(20 \%)$ & & $2 / 9$ & $(12 \%)$ \\
\hline & $<L^{\prime} D^{*}$ & $0 / 10$ & $(0 \%)$ & & $5 / 9$ & $(76 \%)$ \\
\hline & $>\mathrm{LOQ}^{*}$ & $8 / 10$ & $(80 \%)$ & & $2 / 9$ & $(12 \%)$ \\
\hline \multirow[t]{4}{*}{ EVR * } & $12^{\text {th }}$ week & $8 / 10(80 \%)$ & & $2 / 9(12 \%)$ & & \\
\hline & DNO & $2 / 10$ & $(20 \%)$ & & $0 / 9$ & $(0 \%)$ \\
\hline & $<L O D$ & $8 / 10$ & $(80 \%)$ & & $9 / 9$ & $(100 \%)$ \\
\hline & $>$ LOO & 0/10 & $(0 \%)$ & & $0 / 9$ & $(0 \%)$ \\
\hline
\end{tabular}

* For week 4 viral status, LOD and LOO show a relation with treatment outcome ( $p=0,007)$. RT (RVR or EVR) with treatment outcome $(p=0,023)(a=0,05)$.

\section{Early viral response (EVR).}

At 12 weeks, again, the response to treatment was evaluated to see if the patients had an extended RVR (eRVR), an early viral response (EVR) or whether to see if they had an insufficient response and had to abort treatment. The 9 patients who already reported a RVR, were all $\angle L O D$ and therefore were classified as eRVR. Of the 10 remaining patients, 
no patient had a HCV RNA > LOQ, which would result in aborting the treatment. A DNO $\mathrm{HCV}$ was reported in 2 patients and 8 patients were $\angle \mathrm{LOD}$ at 12 weeks. Of the $\mathrm{HCV} \angle L O D$ group $(n=8), 2$ reached a SVR and 6 relapsed after EOT. The 2 patients with a DNO value also relapsed after EOT. After analysis, no relation was found between a DNQ value and the incidence of relapse at 12 weeks $(p=0,474)$. Overall, treatment outcome (SVR or relapsing) showed a relation with the response to therapy (RVR or EVR) $(p=0,023)$ (Table 1).

\section{DNQ during treatment}

From the perspective of treatment outcome and sustained viral response at 24 weeks after treatment, patients were categorized in SVR or Relapse after treatment.

\section{Patients with relapse.}

In total 10 patients reported a relapse 24 weeks after treatment. At the $4^{\text {th }}$ week, 2 patients became negative (<LOO) but had a detectable/ not quantifiable viral load (DNO), and 8/10 (80\%) stayed detectable for HCV viral load on the $4^{\text {th }}$ week (Table 3 ). All 10 patients had a HCV VL $<$ LOQ on the $12^{\text {th }}$ week of treatment and therefore had an adequate response on treatment. At week 12, 2 patients reported a DNO HCV RNA and 8 were <LOD for HCV RNA. These 10 patients did not have a sustained viral load and became detectable within 24 weeks after treatment (Figure 4).

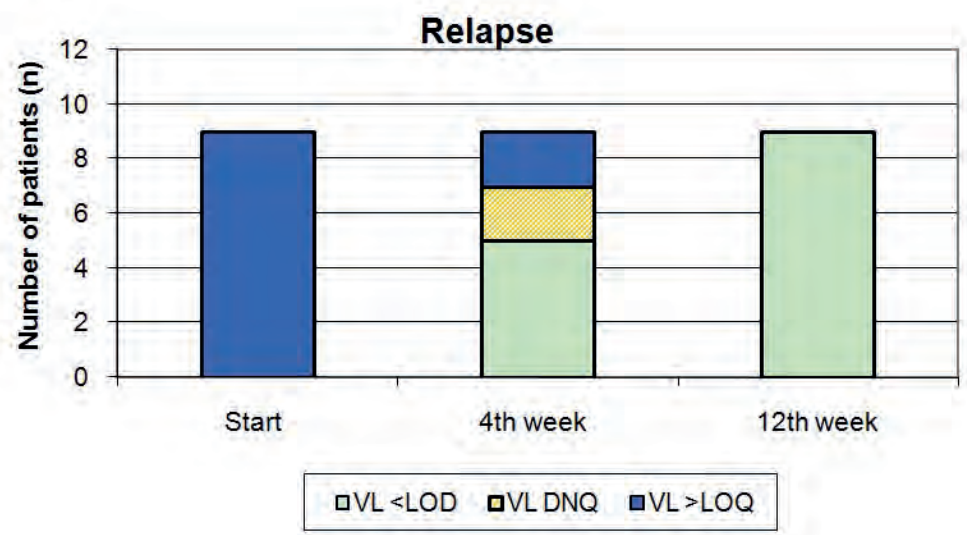




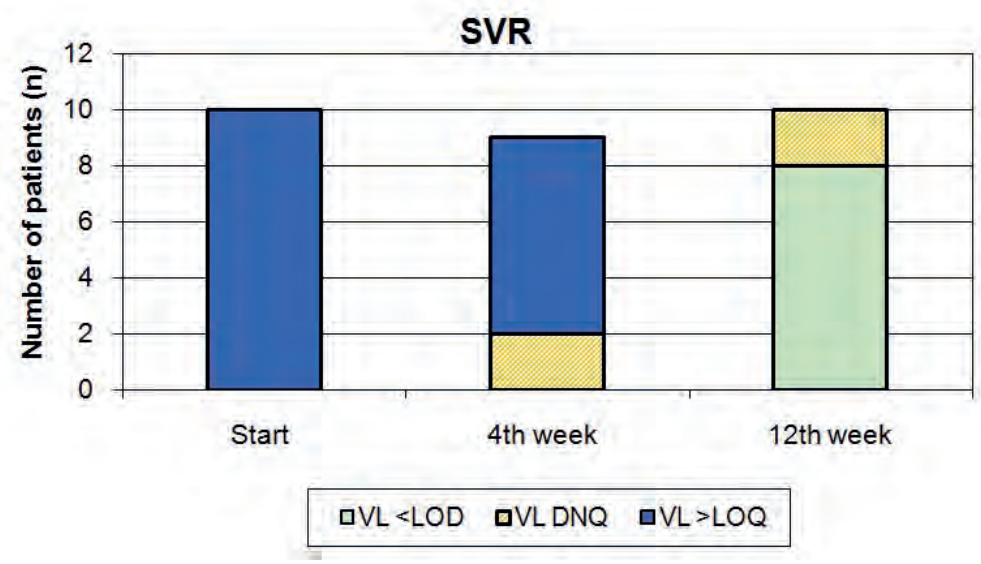

Figure 4. Response to treatment; viral load status at start, $4^{\text {th }}$ and $12^{\text {th }}$ week of treatment: a) Relapse group and b) SVR group. - Number of patients categorized in treatment outcome group (Relapse or SVR) and subdivided in HCV PCR outcome groups. Patients were tested at decision time points during HCV treatment. VL $\angle L O D$; viral load $<15 \mathrm{IU} / \mathrm{ml}$ (undetectable). VL DNQ; HCV viral load between $15 \mathrm{IU} / \mathrm{ml}$ and $43 \mathrm{IU} / \mathrm{ml}$ (detectable/ unquantifiable). VL >LOQ; viral load > $43 \mathrm{lU} / \mathrm{ml}$ (quantifiable). In the relapse group, data of HCV RNA at week 4 is missing.

\section{Patients reaching SVR.}

Of the study cohort, 9 patients reported a SVR at 24 weeks after treatment. At the $4^{\text {th }}$ week of treatment, 7 of these 9 patients reported a HCV RNA $<43 \mathrm{IU} / \mathrm{ml}(<\mathrm{LOO})$ of whom 2 patients had a DNO HCV RNA and 5 had a HCV result <LOD. The 2 remaining patients were detectable ( $>$ LOO) at the $4^{\text {th }}$ week of treatment. At the $12^{\text {th }}$ week of treatment, all 9 patients were reported HCV RNA <LOD and they stayed undetectable for at least 24 weeks after treatment (Figure 4).

Both treatment groups contain patients that became undetectable $(<\mathrm{LOO})$ and patients that stayed detectable ( $>$ LOO) at $4^{\text {th }}$ week of treatment. But not all patients had the predicted treatment outcome, based on the on treatment viral load status at $4^{\text {th }}$ week of treatment. Especially the week 4 DNO values of the relapse group could indicate a relation between treatment outcome and DNQ results. This due to the fact that the relapsing patients were $>\mathrm{LOQ}$ or DNQ, and no $\angle \mathrm{LOD}$ was reported at $4^{\text {th }}$ week of treatment in this group. However, no relation between DNQ at $4^{\text {th }}$ week of treatment and treatment outcome was found $(p=0,167)$

If we look at treatment outcome in relation to having a DNO during treatment, we see that, for 12 patients, the negative HCV RNA results were all <LOD. Of these 12 patients, 7 
patients (58\%) had a SVR and 5 patients (42\%) relapsed within 24 weeks after treatment. In total, 7 patients had at least one DNO HCV RNA result, whereof $71 \%$ relapsed $(n=5)$ and $29 \%(n=2)$ had a sustained viral response (SVR). Analysis of the data showed no relation between DNQ and the incidence of relapse $(p=0,350)$ (Table 2).

Table 2 Sustained viral response (SVR) and Relapse rates according the on-treatment viral load status; DNO or LOD.

\begin{tabular}{|c|c|c|c|c|c|c|}
\hline & Relapse rate & $\mathrm{N}$ & (\%) & SVR Rate & $\mathrm{N}$ & $(\%)$ \\
\hline DNQ & & $5 / 7$ & (71\%) & & $2 / 7$ & (29\%) \\
\hline LOD & & $5 / 12$ & $(42 \%)$ & & $7 / 12$ & $(58 \%)$ \\
\hline
\end{tabular}

\section{Discussion}

The predictive value of the early on-treatment viral response is highly relevant for the treatment of HCV infected patients. Treatment duration is based on HCV RNA results, conducted on decision time points, for which week 4 has been identified as the most valuable SVR predictor (9). In testing HCV viral loads, we depend on the reliability and interpretation of HCV test results, especially in borderline cases. To optimize the interpretation of the results, the differentiation of 'undetectable' from 'detectable' HCV results, might be of relevance. Wrong interpretation could be of great impact on treatment recommendation and the prediction of treatment outcome.

In our study we focused on the effect of 'detectable but not quantifiable' (DNO) HCV results on treatment outcome, in comparison to 'undetectable' (<LOD) HCV Viral loads. Our analysis showed no relation between DNO and the incidence of relapse of infection. Instead our result points out the RVR and EVR as predictor for treatment outcome.

We observed several cases in which a sample was reported as 'undetectable', but truly was only below the limit of quantification and above the limit of detection (LOD). The occurrence of these DNO samples was independent of treatment outcome. So, in our study population, no relation was found between relapsing and having a 'detectable but unquantifiable' HCV RNA value, at any time point during treatment.

Week 4 samples. At the week 4 decision time point, HCV RNA > LOQ or <LOD were predictive for the treatment outcome at SVR24, but the DNO showed no relation with relapsing. Of the 4 patients with a DNO HCV result at week 4 of treatment, 2 relapsed and 2 had a SVR at 24 weeks after end of treatment. If DNO is interpreted as detectable, this would indicate an altered treatment recommendation (7), but only 2 patients relapsed ultimately. Therefore making alterations to treatment, based on DNO values at week 4, might lead to unnecessary prolonged treatment duration. 
Week 12 samples. At week 12 no single DNO value was found in the SVR group, in contrast to the relapsed patient group, in which two patients of this group were observed with a DNO at week 12. This might indicate an altered treatment recommendation for DNO HCV results at week 12, but, in our study, no significant relation between DNO and treatment outcome was observed at week 12.

The specificity of modern HCV RNA PCR assay's are extremely high, therefore truly HCV RNA negative samples are not often misclassified (13). However, the cut-off value is determined by the limit of detection (LOD) of the used PCR, which represents a $95 \%$ detection rate of the lowest actual HCV RNA. This means that in $5 \%$ of the samples, who are equal to the LOD, are not detected $(11,12)$. Therefore an 'undetectable' HCV RNA result does not necessarily guarantee a total absence of HCV RNA. In samples with a HCV RNA equal to LOD, the results will fluctuate between 'undetectable' and 'detectable/not quantifiable' (DNO).

Another disadvantage of using this technique in samples with low HCV levels, is that within each replication cycle, the DNA in the sample is doubled. However the fluorescence is only determined after completion of the cycle and not during the cycle (10). This results in a standard deviation of LOG 0,248 in samples with low HCV contractions (14). The difference between a DNQ and >LOQ or a $<$ LOD and DNQ result, could be within one cycle. This implies that the detection of a borderline sample is based on chance instead of valid test outcomes.

Next to this, preparation of borderline cases with very low amounts of viral particles, is likely to contribute to inaccuracy of test results. Only a small quantity is taken from the sample, which might, in case of a low concentration of virons, lead to testing a volume in which no virus is present. This could lead to false negative detection, but also to false positive classification of HCV. No validation of pipetting accuracy is preformed for HCV analysis in the laboratory MUMC+.

The findings of this study are not confirmed by the studies of Harrington et al (10) and Maasoumy et al (9). They showed a relation between a DNO at $4^{\text {th }}$ week of treatment and an increased rate of relapsing after end of treatment. It should be mentioned that these studies used specific inclusion criteria like HCV genotype and medication, which were not used in our study. Furthermore, they speak of possible false positive detection of HCV RNA (Harrington et al.) (10) and that retesting of the samples improves SVR prediction (Maasoumy et al.) (9), which in turn might lead to unnecessary repeat testing. In our study, reporting a DNO as false positive or false negative, does not change the clinical relevance, as DNO values showed no relation with relapsing at 4 week or week 12 of treatment.

Our study clearly has some limitation. We used a retrospective study design in combination 
with a relatively small and heterogonous study cohort. Therefore, the study cohort should be extended to adequately powered and more homogenous cohorts. Furthermore, due to the small study cohort and lack of data, associated risk factors and treatment predictors like IL28, HCV genotype, Cirrhosis, HBV, HIV co-infection, MSM contacts and age were not taken into account. Thus, future studies should include more predictive factors and risk factors to get a clear understanding of possible influences. It is well known that HCV infection is transmitted by MSM contacts and injection drug use. These risk factors for infection are not specifically taken into account. A possible explanation for "relapsing" patients, might be re-infection due to exposure to blood or blood-derived body fluids of an untreated HCV carrier. It is often seen that HCV genotypes are region specific, therefore determining HCV genotype is often not useful for identifying a re-infection in these risk groups. In our study, we also did not subdivided patients based on used medication and treatment duration. Not taking these possible important factors in account, might blur the identification or cohesion of additional predictive factors.

\section{Conclusion}

Based on results presented in this report, we conclude that not the interpretation of the DNQ, but the time point on which a HCV RNA is "undetectable", is of high clinical relevance in reaching SVR. In addition, the question if a detectable/ not quantifiable HCV result should be considered as false positive or false negative, is not clinically relevant. Nevertheless, using the LOO as cut-off for making the RGT decisions, which is a validated and accepted cut-off limit, will not guarantee the predicted treatment outcome. Therefore, regarding only the LOQ cut-off value, without other predictors and risk factors, may put some patients at risk of receiving a sub therapeutic treatment duration. However, patients with a truly negative HCV RNA at week 4 , have a good prospect of achieving a SVR. We conclude that, the already identified predictors, RVR and EVR have a stronger predictive value for treatment outcome, than being detectable but not quantifiable at these specific time points. Therefore, our study suggests that no changes in the decision-rules for HCV treatment, have to be carried out.

\section{Role of the student}

B.C.M. Conjaerts was an undergraduate student in Biomedical Science working under the supervision of A.M.L. Oude Lashof and P.G.F. Wolffs when the research in this report was preformed. The topic was proposed by A.M.L Oude Lashof. The design of the study, the processing of the results as well as the formulation of the conclusions and the writing were done by the student. 


\section{References}

1. Andre P, Komurian-Pradel F, Deforges S, Perret M, Berland JL, Sodoyer M, et al. Characterization of low- and very-low-density hepatitis C virus RNA-containing particles. Journal of virology. 2002 Jul;76(14):69-28.

2. Agnello V, Abel G, Elfahal M, Knight GB, Zhang OX. Hepatitis C virus and other flaviviridae viruses enter cells via low density lipoprotein receptor. Proceedings of the National Academy of Sciences of the United States of America. 1999 Oct 26;96(22):12766-71. PubMed PMID: 10535997. Pubmed Central PMCID: 23090.

3. Coller KE, Heaton NS, Berger KL, Cooper JD, Saunders JL, Randall G. Molecular determinants and dynamics of hepatitis C virus secretion. PLoS pathogens. 2012 Jan;8(1):e1002466. PubMed PMID: 22241992. Pubmed Central PMCID: 3252379 .

4. Lavanchy D. Evolving epidemiology of hepatitis C virus. Clinical microbiology and infection : the official publication of the European Society of Clinical Microbiology and Infectious Diseases. 2011 Feb;17(2):107-15. PubMed PMID: 21091831.

5. Vriend HJ, Van Veen MG, Prins M, Urbanus AT, Boot HJ, Op De Coul EL. Hepatitis C virus prevalence in The Netherlands: migrants account for most infections. Epidemiology and infection. 2013 Jun;141(6):1310-7. PubMed PMID: 22963908

6. McCombs JS, Yuan Y, Shin J, Saab S. Economic burden associated with patients diagnosed with hepatitis C. Clinical therapeutics. 2011 Sep;33(9):1268-80. PubMed PMID: 21840056.

7. Ghany MG, Nelson DR, Strader DB, Thomas DL, Seeff LB, American Association for Study of Liver D. An update on treatment of genotype 1 chronic hepatitis $C$ virus infection: 2011 practice guideline by the American Association for the Study of Liver Diseases. Hepatology. 2011 Oct;54(4):1433-44. PubMed PMID: 21898493. Pubmed Central PMCID: 3229841.

8. Yang JH, Lai JP, Douglas SD, Metzger D, Zhu XH, Ho WZ. Real-time RT-PCR for quantitation of hepatitis C virus RNA. Journal of virological methods. 2002 Apr;102(1-2):119-28. PubMed PMID: 11879700.

9. Maasoumy B, Cobb B, Bremer B, Luk K, Halfon P, Aslam S, et al. Detection of low HCV viraemia by repeated HCV RNA testing predicts treatment failure to triple therapy with telaprevir. Alimentary pharmacology \& therapeutics. 2014 Jan;39(1):85-92. PubMed PMID: 24206524.

10. Harrington PR, Zeng W, Naeger LK. Clinical relevance of detectable but not quantifiable hepatitis C virus RNA during boceprevir or telaprevir treatment. Hepatology. 2012 Apr;55(4):1048-57. PubMed PMID: 22095516.

11. Yu JW, Wang GO, Sun LJ, Li XG, Li SC. Predictive value of rapid virological response and early virological response on sustained virological response in $\mathrm{HCV}$ patients treated with pegylated interferon alpha-2a and ribavirin. Journal of gastroenterology and hepatology. 2007 Jun;22(6):832-6. PubMed PMID: 17565637.

12. Gupta E, Bajpai M, Choudhary A. Hepatitis C virus: Screening, diagnosis, and interpretation of laboratory assays. Asian journal of transfusion science. 2014 Jan;8(1):19-25. PubMed PMID: 24678168. Pubmed Central PMCID: 3943138.

13. Roche Molecular Systems. COBAS AmpliPrep/COBAS TaqMan HCV Test Package Insert. 2008. Available from: http://www.accessdata.fda.gov/cdrh_docs/pdf6/Po6oozoc.pdf.

14. Sulkowski MS, Gardiner DF, Rodriguez-Torres M, Reddy KR, Hassanein T, Jacobson I, et al. Daclatasvir plus sofosbuvir for previously treated or untreated chronic HCV infection. The New England journal of medicine. 2014 Jan 16;370(3):211-21. PubMed PMID: 24428467. 